\title{
A Journey through Virtual and Augmented Reality - Reviewing the SVR Symposia from 2004 to 2008
}

\author{
Alberto Raposo ${ }^{1}$ \\ Judith Kelner ${ }^{2}$ \\ Luciano Soares ${ }^{1}$ \\ Veronica Teichrieb ${ }^{2}$
}

\begin{abstract}
This article intends to provide a panorama of the Brazilian Symposium on Virtual and Augmented Reality (SVR) based on the analysis of its last four editions (2004, 2006, 2007, and 2008). We had reviewed the 124 full papers published in these four editions of the symposium and had analyzed them according to different criteria. These criteria include research topics, technologies used, and research approaches. The goal of this document is to draw an accurate picture of the research in this area in Brazil and try to provide insights about trends, deficiencies, and opportunities that may help guiding future efforts of the Brazilian research community in virtual and augmented reality.
\end{abstract}

1 Computer Graphics Technology Group - Tecgraf, Computer Science Department - DI, Pontifical Catholic University of Rio de Janeiro - PUC-Rio, Rua Marquês de São Vicente, 225, Prédio Belisário Velloso, 22453-900, Rio de Janeiro, Rio de Janeiro, Brazil \{abraposo, lpsoaresdtecgraf.puc-rio.br\}

2 Virtual Reality and Multimedia Research Group - GRVM, Computer Science Center - CIn, Federal University of Pernambuco - UFPE, Av. Professor Moraes Rego S/N, Prédio da Positiva, $1^{\circ}$ Andar, Cidade Universitária, 50670-901, Recife, Pernambuco, Brazil $\{j k$, vtecin.ufpe.br $\}$ 


\section{Introduction}

Like the authors of this paper, there are several researchers in Brazil that have been participating in SVR symposia and committees for the past years. We probably have intuitions about how the event has evolved throughout the years and how research focuses and technologies have been changing. However, we do not have an accurate picture of how our community has been conducting research in Virtual Reality (VR) and related areas. Therefore, we had the idea of using this special issue of RITA to provide such picture, based on an analysis of the full papers presented in the last four SVR editions, which is the most important Brazilian event in the area. The last editions of SVR occurred in: São Paulo, 2004 [1]; Belém, 2006 [2]; Petrópolis, 2007 [3]; and João Pessoa, 2008 [4].

In order to perform such analysis we read the 124 full papers in these last four editions (2004 - 28 papers; 2006 - 37 papers; 2007 - 35 papers; and 2008 - 24 papers) and classified them according to some criteria we judged relevant to draw a scenario. These criteria may provide insights that help indicating research trends and opportunities as well as calling the attention about drawbacks and limitations.

We started our analysis with some basic statistics (Section 2) about the number of papers written in English and Portuguese, and the international participation. In Section 3 we examine how papers have been distributed among the major subjects covered by the symposium. Section 4 presents the scrutiny of the most important technologies used. Finally, Section 5 discusses research approaches applied by the reviewed papers.

Since some of the classification criteria are prone to different interpretations, we adopted a methodology that each one of the four authors of this paper would read and classify the 124 papers separately. After that, the classifications were compared and the differences and doubts were discussed until we reached a consensus about the best classification approach. Since we do not have space to provide a reference to all the 124 papers, we used a code to describe them: YYpXX means the paper that starts at page XX of the proceedings of SVR 20YY. For example, 06p89 means the paper in the proceedings of SVR 2006 starting at page 89.

\section{Some Statistics about SVR}

Since the year 2001, many SVR committees have been encouraging international participation and the publication of papers written in the English and Portuguese languages. This initiative has lead to a number of Brazilian researchers writing their papers in English, hence giving a better international visibility to recent VR and Augmented Reality (AR) advances achieved in Brazil. We present an evaluation of the progress made by examining the last four editions only. A number of statistics showing a sizeable increase of English written papers published in these recent years prove such stable trend. Figure 1 presents the 
number of papers published in the event written in both languages. Although the absolute number of such articles in 2008 is smaller than in the previous years, the relative number shows a proportional increase when considering the number of published Portuguese papers. Whereas in 2004, only around $21 \%$ of the papers were written in English, this number reached roughly $48 \%$ in the 2006 version of the event. The level of participation continued in its growing trend reaching approximately 51\% and 62.5\% in 2007 and 2008 respectively.

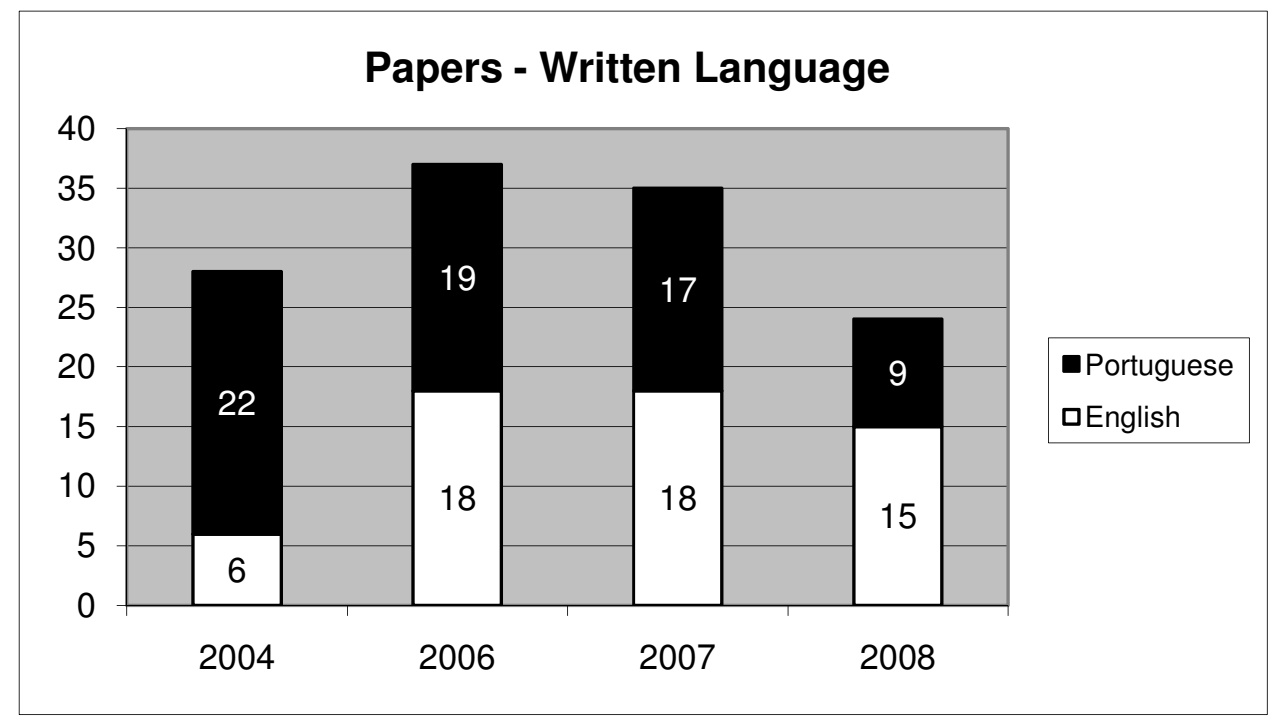

Figure 1. Papers published in SVR both in English and Portuguese language

To further enforce the internationalization of SVR papers, those written in English must also be presented in this language at the symposium. There has also been a considerable increase in the number of non-Brazilian researchers who submitted their works to SVR and the number of accepted papers for non-Brazilian authors is shown in Figure 2. Although there was a decline in the absolute number of international papers in 2008, their share of participation increased (as stated before in the analysis of Figure 1). Similarly, SVR enjoyed $10 \%$ of international participation in 2006; in 2007 was roughly 14\%, and in 2008 it reached $16 \%$. 


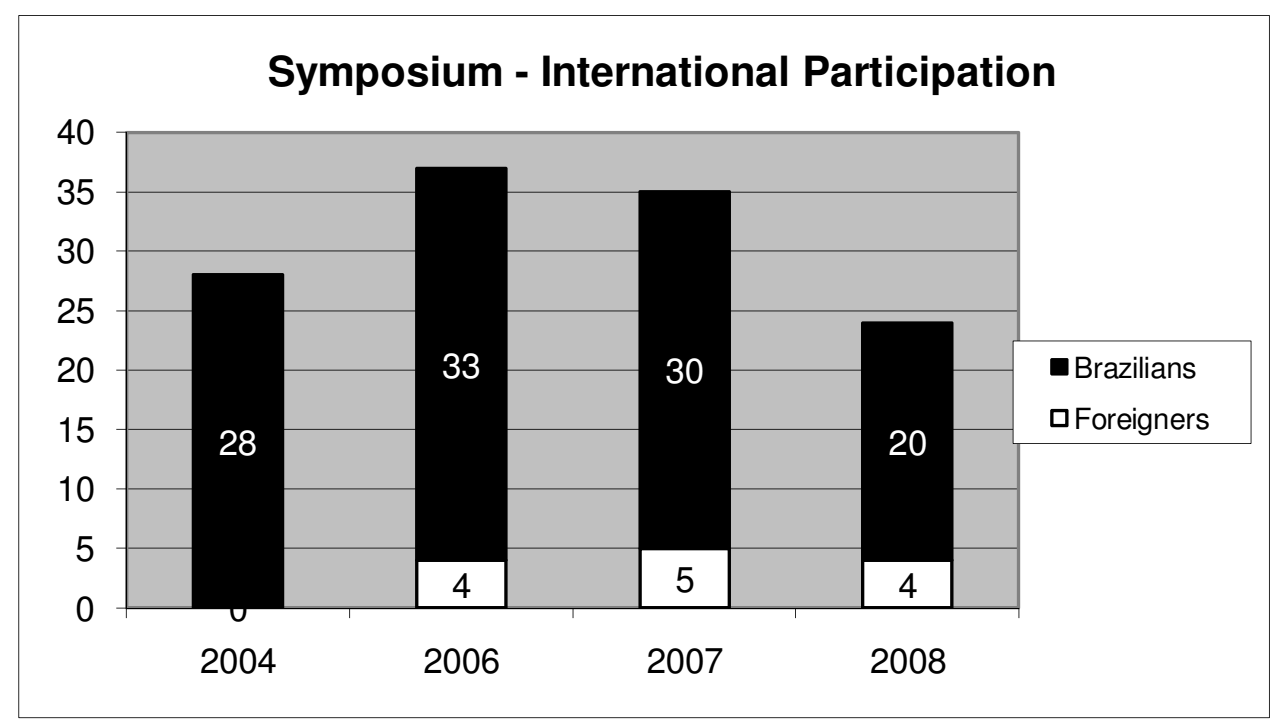

Figure 2. International participation in papers published at SVR

\section{Major Subjects Published at SVR}

SVR tries to be a multidisciplinary event, and accepts papers from several areas within the VR and AR areas, allowing researchers from different domains to publish their work in the symposium proceedings. Reviewing some of the more recent papers published, we noticed that the subjects themselves are not in constant change as expected, but the proportion of papers in these different subjects has been smoothly changing. Since the number of papers in each subject per year is usually low, it is difficult to confirm a research direction. Based on a summary of the topics that traditionally appear in the call for papers and in the proceedings, we present, in this article, how the papers are distributed among our concerned major subjects.

VR applied to medicine, educational and industrial applications is a constant presence in the publications, but it is possible to note that medicine is being more exploited than any other application field. Analyzing Table 1 we can find out that about $56 \%$ of the application papers deal with medicine research, while $16 \%$ is about education and $26 \%$ about industry. Several tools and techniques for the development of VR applications appeared in the last years, especially in the last event, but it is not possible to correlate these tools with final applications. It is clear that the SVR community started paying more attention to offer tools for the development of VR and AR applications, avoiding replication of work already done by others research institutions. 
Table 1. Papers related to specific application domains.

\begin{tabular}{|l|l|}
\hline \multicolumn{1}{|c|}{ Area } & \multicolumn{1}{|c|}{ Year and page reference } \\
\hline Medicine & $04 \mathrm{p} 171 ; 04 \mathrm{p} 183 ; 04 \mathrm{p} 195 ;$ \\
& $06 \mathrm{p} 3 ; 06 \mathrm{p} 15 ; 06 \mathrm{p} 27 ; 06 \mathrm{p} 39 ; 06 \mathrm{p} 51 ; 06 \mathrm{p} 387 ; 06 \mathrm{p} 397 ; 06 \mathrm{p} 421 ; 06 \mathrm{p} 433 ; 06 \mathrm{p} 445 ;$ \\
& $07 \mathrm{p} 44 ; 07 \mathrm{p} 100 ; 07 \mathrm{p} 253 ;$ \\
& $08 \mathrm{p} 233$ \\
\hline Education & $04 \mathrm{p} 231 ; 04 \mathrm{p} 265 ;$ \\
& $06 \mathrm{p} 409 ;$ \\
& $07 \mathrm{p} 246 ;$ \\
& $08 \mathrm{p} 322$ \\
\hline Industry & $04 \mathrm{p} 88 ; 04327 ;$ \\
& $06 \mathrm{p} 147 ; 06 \mathrm{p} 285 ;$ \\
& $07 \mathrm{p} 278 ; 07 \mathrm{p} 286 ;$ \\
& $08 \mathrm{p} 81 ; 08 \mathrm{p} 143$ \\
\hline VR & $04 \mathrm{p} 3 ; 04 \mathrm{p} 15 ; 04 \mathrm{p} 51 ;$ \\
Techniques & $06 \mathrm{p} 65 ; 06 \mathrm{p} 171 ; 06 \mathrm{p} 271 ;$ \\
and Tools & $07 \mathrm{p} 162 ;$ \\
& $08 \mathrm{p} 61 ; 08 \mathrm{p} 251 ; 08 \mathrm{p} 307 ; 08 \mathrm{p} 313$ \\
\hline
\end{tabular}

$\mathrm{AR}$ is getting more attention from the academic researchers in the last years, as presented in Table 2. In 2004 there were three papers in this field, in 2006 there were four and in 2007 six papers were published. The year 2008 had three papers but probably due the overall smaller amount of publications in this symposium. The mixed reality area is other research domain that is always present but usually just one paper is accepted per event.

Table 2. Papers in the AR and mixed reality areas.

\begin{tabular}{|l|l|}
\hline \multicolumn{1}{|c|}{ Area } & \multicolumn{1}{|c|}{ Year and page reference } \\
\hline Augmented & $04 \mathrm{p} 113 ; 04 \mathrm{p} 149 ; 04 \mathrm{p} 161 ;$ \\
Reality & $06 \mathrm{p} 89 ; 06 \mathrm{p} 121 ; 06 \mathrm{p} 221 ; 06 \mathrm{p} 337 ;$ \\
& $07 \mathrm{p} 51 ; 07 \mathrm{p} 92 ; 07 \mathrm{p} 106 ; 07 \mathrm{p} 207 ; 07 \mathrm{p} 217 ; 07 \mathrm{p} 271 ;$ \\
& $08 \mathrm{p} 28 ; 08 \mathrm{p} 185 ; 08 \mathrm{p} 196$ \\
\hline Mixed Reality & $04 \mathrm{p} 124 ;$ \\
& $07 \mathrm{p} 152 ;$ \\
& $08 \mathrm{p} 36$ \\
\hline
\end{tabular}

Interaction research has being realized by the development of software techniques and hardware resources. Based on Table 3, we can see a constant amount of papers dealing with interaction approaches, highlighting that this is an important area in the VR field. Interaction is still open for more research and the development of new techniques. About three papers per year discuss this area. Input and output devices presented in the publications are very commonly low cost driven. Pure haptics research systems are always present, but still need to increase their participation. Most of the SVR community is not working in this area, 
different from other VR conferences across the world, where haptics is an important research field.

Table 3. Papers discussing interaction issues.

\begin{tabular}{|l|l|}
\hline \multicolumn{1}{|c|}{ Area } & \multicolumn{1}{|c|}{ Year and page reference } \\
\hline 3D Software Interaction & $04 \mathrm{p} 76 ;$ \\
& $06 \mathrm{p} 77 ; 06 \mathrm{p} 233 ; 06 \mathrm{p} 349 ;$ \\
& $07 \mathrm{p} 30 ; 07 \mathrm{p} 77 ; 07 \mathrm{p} 143 ; 07 \mathrm{p} 197 ;$ \\
& $08 \mathrm{p} 212 ; 08 \mathrm{p} 115$ \\
\hline VR Input Devices & $06 \mathrm{p} 259 ; 06 \mathrm{p} 309 ; 06 \mathrm{p} 323 ;$ \\
& $07 \mathrm{p} 17 ; 07 \mathrm{p} 68 ;$ \\
& $08 \mathrm{p} 204$ \\
\hline VR Output Devices & $06 \mathrm{p} 51 ;$ \\
& $07 \mathrm{p} 3 ; 07 \mathrm{p} 60 ; 07 \mathrm{p} 68$ \\
\hline Pure Haptics & $04 \mathrm{p} 65 ;$ \\
& $06 \mathrm{p} 135 ;$ \\
\hline
\end{tabular}

Avatars are a very specific area in VR that has always a good amount of papers presenting their different forms of use. In the last four SVR proceedings we were able to find nine papers discussing the use of avatars. Artificial life is presented in most of the events, but with a smaller participation. The SVR community has decreased the number of research papers in the collaborative and distributed environments in the last two years; just one paper was published each year as shown in Table 4.

Table 4. Papers about avatars, artificial life and distributed/collaborative areas.

\begin{tabular}{|l|l|}
\hline \multicolumn{1}{|c|}{ Area } & \multicolumn{1}{|c|}{ Year and page reference } \\
\hline Avatars & $04 \mathrm{p} 27 ; 04 \mathrm{p} 243 ; 04 \mathrm{p} 315 ;$ \\
& $06 \mathrm{p} 197 ; 06 \mathrm{p} 209 ;$ \\
& $07 \mathrm{p} 84 ; 07 \mathrm{p} 170 ; 07 \mathrm{p} 180 ;$ \\
& $08 \mathrm{p} 348$ \\
\hline Artificial Life & $04 \mathrm{p} 39 ; 04 \mathrm{p} 217 ;$ \\
& $06 \mathrm{p} 245 ;$ \\
& $07 \mathrm{p} 187 ; 07 \mathrm{p} 236 ;$ \\
& $08 \mathrm{p} 337$ \\
\hline Distributed & $04 \mathrm{p} 255 ; 04 \mathrm{p} 303 ;$ \\
Collaborative & $06 \mathrm{p} 373 ; 06 \mathrm{p} 397 ;$ \\
& $07 \mathrm{p} 263 ;$ \\
\hline & $08 \mathrm{p} 143$ \\
\hline
\end{tabular}

Table 5 presents the fact that real-time simulations and visualizations that are traditional applied areas in VR were not very well exploited in the past symposia. We noted that in 2008 this topic was contemplated with four papers. On the other hand, computer graphics techniques have a low participation in the symposia, probably due to the fact that this area has other specific conference in Brazil. 
Table 5. Papers in real-time simulations, visualization and pure computer graphics areas.

\begin{tabular}{|l|l|}
\hline \multicolumn{1}{|c|}{ Area } & \multicolumn{1}{|c|}{ Year and page reference } \\
\hline Real-Time Simulations & $04 \mathrm{p} 100 ;$ \\
and Visualization & $06 \mathrm{p} 297 ; 06 \mathrm{p} 361 ;$ \\
& $07 \mathrm{p} 116 ; 07 \mathrm{p} 123 ; 07 \mathrm{p} 133 ; 07 \mathrm{p} 227 ;$ \\
& $08 \mathrm{p} 21 ; 08 \mathrm{p} 105 ; 08 \mathrm{p} 233 ; 08 \mathrm{p} 241$ \\
\hline Pure Computer & $04 \mathrm{p} 137 ; 04 \mathrm{p} 207 ;$ \\
Graphics & $06 \mathrm{p} 147 ;$ \\
& $08 \mathrm{p} 223$ \\
\hline
\end{tabular}

Finally, there are some papers which not fell into our classification, as presented in Table 6. These subjects include mobile devices, video transmission and so on. The symposium welcomes these kinds of publications, in spite of not being in the core of VR and AR.

Table 6. Papers related to other subjects.

\begin{tabular}{|c|l|}
\hline Area & \multicolumn{1}{|c|}{ Year and page reference } \\
\hline Other areas & $04 \mathrm{p} 279 ; 04 \mathrm{p} 291 ;$ \\
& $06 \mathrm{p} 101 ; 06 \mathrm{p} 113 ; 06 \mathrm{p} 159 ; 06 \mathrm{p} 183 ;$ \\
& $07 \mathrm{p} 24 ; 07 \mathrm{p} 10 ;$ \\
& $08 \mathrm{p} 70 ; 08 \mathrm{p} 151 ; 08 \mathrm{p} 359$ \\
\hline
\end{tabular}

\section{Most Important Technologies Used}

This section describes some of the technologies raised by SVR researchers when developing their VR and AR projects. Firstly, several of the SVR articles exploited 3D web based languages, as presented in Table 7. For example, during the SVR 2004 and 2006, a great deal of papers was based on the VRML language (six papers and nine papers, respectively). This may be attributed, in our view, to the fact that VRML is an open standard and has several browsers freely available, in addition to its easy learning. However, we see since 2008 event that with the advent of X3D for standardization of 3D in the web, researchers are moving towards this new technology.

Table 7. Papers related to 3D web based technologies.

\begin{tabular}{|l|l|}
\hline Technology & \multicolumn{1}{|c|}{ Year and page reference } \\
\hline VRML & 04p3; 04p195; 04p231; 04p255; 04p279; 04p303; \\
& 06p3; 06p15; 06p147; 06p159; 06p233; 06p397; 06p409; 06p421; 06p445; \\
& 07p100;07p271;07p278; \\
& 08p185 \\
\hline X3D & 04p27; 04p291; \\
& 06p27; \\
& $08 p 61 ; 08 p 115$ \\
\hline
\end{tabular}


Another point to highlight is the tendency for using technologies already consolidated in the computer graphics and game research areas. These include graphics rendering and physics simulation engines and libraries, depicted in Table 8. In the first SVR editions, many of the published works did not consider (roughly six papers) graphic realism in their design tools. Recently, the community started actively focusing not only on graphics rendering using popular engines like OGRE, OSG and VTK but also experimenting with physics modeling supported by engines such as PhysX and ODE, corresponding about $34 \%$ of the publications. Traditionally, these engines work as an abstraction layer for graphics libraries such as OpenGL. But, most of the papers use such low level libraries directly, mainly due performance issues. It is important to state that these technologies are also open source and freely licensed. Further, they are object-oriented which facilitates program development. Consequently, recent works have been able to achieve higher levels of graphic realism. We have noticed that some papers exploit some specific libraries that do not couple with our major classification.

Table 8. Papers about graphics rendering and physics simulation engines and libraries.

\begin{tabular}{|l|l|}
\hline Technology & \\
\hline OGRE & $06 \mathrm{p} 65 ; 06 \mathrm{p} 271 ; 06 \mathrm{p} 285 ;$ \\
& $07 \mathrm{p} 68 ; 07 \mathrm{p} 77 ;$ \\
& $08 \mathrm{p} 223 ; 08 \mathrm{p} 251$ \\
\hline OSG & $04 \mathrm{p} 327 ;$ \\
& $07 \mathrm{p} 152 ; 07 \mathrm{p} 236 ;$ \\
& $08 \mathrm{p} 307 ; 08 \mathrm{p} 337$ \\
\hline VTK & $04 \mathrm{p} 88 ;$ \\
& $06 \mathrm{p} 147 ;$ \\
& $08 \mathrm{p} 233$ \\
\hline PhysX & $08 \mathrm{p} 251$ \\
\hline ODE & $06 \mathrm{p} 197 ;$ \\
& $07 \mathrm{p} 187 ; 07 \mathrm{p} 227 ;$ \\
& $08 \mathrm{p} 241 ; 08 \mathrm{p} 337 ; 08 \mathrm{p} 251$ \\
\hline OpenGL & $04 \mathrm{p} 100 ; 04 \mathrm{p} 183 ;$ \\
& $06 \mathrm{p} 3 ; 06 \mathrm{p} 51 ; 06 \mathrm{p} 77 ; 06 \mathrm{p} 101 ; 06 \mathrm{p} 121 ; 06 \mathrm{p} 197 ; 06 \mathrm{p} 271 ; 06 \mathrm{p} 285 ; 06 \mathrm{p} 297 ;$ \\
& $06 \mathrm{p} 337 ; 06 \mathrm{p} 387 ; 06 \mathrm{p} 445 ;$ \\
& $07 \mathrm{p} 17 ; 07 \mathrm{p} 30 ; 07 \mathrm{p} 123 ; 07 \mathrm{p} 207 ;$ \\
\hline Others & $08 \mathrm{p} 36 ; 08 \mathrm{p} 241$ \\
\hline libraries & $04 \mathrm{p} 15 ; 04 \mathrm{p} 39 ;$ \\
& $06 \mathrm{p} 361 ;$ \\
& $07 \mathrm{p} 36 ; 07 \mathrm{p} 278 ;$ \\
\hline
\end{tabular}


The year 2004 saw the introduction of AR to the SVR community. The ARToolKit library was a major force behind such action, being used by three papers. This fact was seen as a global tendency as the ARToolKit implements a complete AR pipeline, making application development straightforward. The amount of three papers published in 2004 remained stable in the subsequent symposia. In the following events, some research projects moved to other AR technologies such as the ARTag (one paper in 2008) and the computer vision library OpenCV (about two papers per year), as presented in Table 9. These tools offered more sophisticated functionalities and could be used to improve existing applications. Nowadays, with the expansion of AR research, some complex software infrastructures are being built from the scratch as highlighted by corresponding publications in SVR.

Table 9. Papers focused on augmented reality technologies.

\begin{tabular}{|l|l|}
\hline Technology & \multicolumn{1}{|c|}{ Year and page reference } \\
\hline ARToolKit & $04 \mathrm{p} 113 ; 04 \mathrm{p} 149 ; 04 \mathrm{p} 161 ;$ \\
& $06 \mathrm{p} 89 ; 06 \mathrm{p} 121 ; 06 \mathrm{p} 221 ;$ \\
& $07 \mathrm{p} 17 ; 07 \mathrm{p} 24 ; 07 \mathrm{p} 123 ; 07 \mathrm{p} 207 ; 07 \mathrm{p} 271 ;$ \\
& $08 \mathrm{p} 36$ \\
\hline ARTag & $08 \mathrm{p} 185$ \\
\hline OpenCV & $06 \mathrm{p} 259 ;$ \\
& $07 \mathrm{p} 92 ; 07 \mathrm{p} 116 ;$ \\
& $08 \mathrm{p} 105 ; 08 \mathrm{p} 212$ \\
\hline
\end{tabular}

Regarding the use of programming languages $\mathrm{C}$-like languages $(\mathrm{C} / \mathrm{C}++$ and $\mathrm{C \#})$ appearing with forty three papers and Java with twenty five papers (used in association with Java 3D) have been at the forefront. This is in line with global initiatives. With the use of complex graphics and physics libraries, performance had become an issue. This leads the adoption of low level languages such as $\mathrm{C} / \mathrm{C}++$. On the other hand, Java like languages showed to be a good candidate for web based applications and standalone tools. XML has also been used for standardization purposes more emphatically since 2007 (about three papers per year). It is visible that many papers did not explicit which language is used, being around $42 \%$ of all publications. Table 10 presents our analysis. 
Table 10. Papers using specific programming languages.

\begin{tabular}{|c|c|}
\hline Technology & Year and page reference \\
\hline C-like & $\begin{array}{l}\text { 04p88; 04p183; } \\
\text { 06p3; 06p65; 06p77; 06p101; 06p147; 06p159; 06p197; 06p271; 06p285; } \\
\text { 06p297; 06p361; 06p387; 06p421;06p445; } \\
\text { 07p3; 07p10; 07p17; 07p30; 07p44; 07p68; 07p77; 07p92; 07p100; } \\
\text { 07p106; 07p116; 07p123; 07p180;07p187;07p197;07p227; } \\
\text { 08p21; 08p81; 08p185; 08p204;08p212;08p223;08p233;08p241; } \\
\text { 08p251; 08p313; 08p337 }\end{array}$ \\
\hline Java-like & 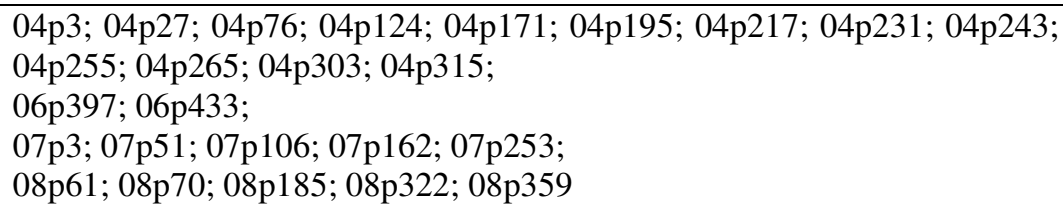 \\
\hline $\mathrm{Cg}$ & $\begin{array}{l}\text { 04p100; } \\
08 \text { p185; 08p223 }\end{array}$ \\
\hline XML & $\begin{array}{l}\text { 04p27; 04p291; } \\
\text { 06p27; } \\
\text { 07p3; 07p180; 07p286; } \\
\text { 08p61; 08p70;08p143; 08p307 }\end{array}$ \\
\hline $\begin{array}{l}\text { Non } \\
\text { identified }\end{array}$ & 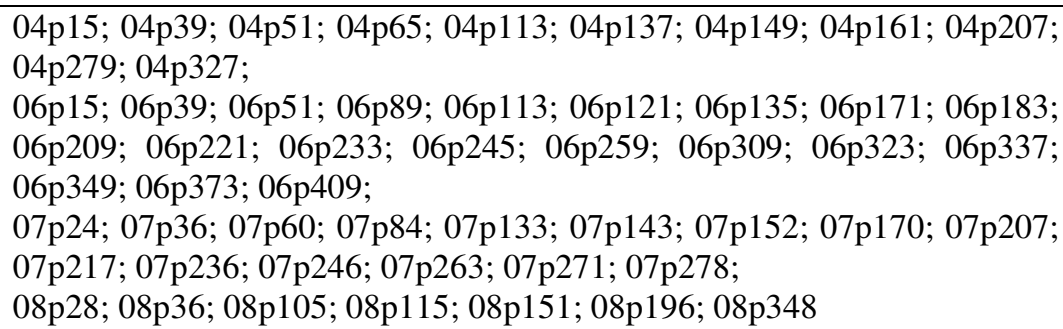 \\
\hline
\end{tabular}

Due to the strong relationship between the computer graphics and VR and AR areas, many authors exploited this to improve their designs. There was consequently a surge in the use of specialized graphics boards, programmed with languages such as $\mathrm{Cg}$ (see Table 10). These new hardware resources have been taken advantage of to increase performance and graphics realism quality.

The SVR community not only focuses on software development, but also embraces works based on the development and application of specialized hardware systems, as shown in Table 11. While not only using devices such as Head Mounted Displays (HMDs), some of these works used stereoscopy hardware, as well as software, to developed specific applications for immersive display systems (about $13 \%$ of published papers). Others SVR 
papers described the development of hardware in order to build new interaction devices, including haptic ones. Their integration with applications was based on the use of open libraries such as OpenHaptics. Similarly to the interaction with the computer graphics area, a new tie was made with the hardware community. Although such interdisciplinary cooperation was observed over a limited number of projects (around 9\% of published papers), it remains relevant and demonstrates the natural multidisciplinary aspect of the SVR symposium.

Table 11. Papers related to technologies for hardware systems development.

\begin{tabular}{|c|c|}
\hline Technology & Year and page reference \\
\hline $\begin{array}{l}\text { Stereoscopic } \\
\text { hardware / } \\
\text { software } \\
\text { based }\end{array}$ & $\begin{array}{l}\text { 04p124; 04p183; 04p217; 04p265; } \\
\text { 06p3; 06p77; 06p183; } \\
\text { 07p10; 07p36; 07p68; 07p77; 07p143; 07p152;07p236; 07p278; } \\
\text { 08p70 }\end{array}$ \\
\hline Haptics & $\begin{array}{l}04 p 65 ; \\
06 p 135 ; 06 p 309 ; 06 p 445\end{array}$ \\
\hline $\begin{array}{l}\text { Hardware- } \\
\text { based }\end{array}$ & $\begin{array}{l}\text { 04p113; } \\
\text { 06p51;06p323; } \\
\text { 07p17; 07p24; 07p36; 07p68; 07p92;07p106; } \\
\text { 08p70; 08p185 }\end{array}$ \\
\hline
\end{tabular}

In our final remarks on SVR relevant technologies, it is important to mention that not all research work fell into the areas presented so far. Some went all the way to develop technologies to answer their specific project requirements. These included software libraries, open sources for graphics tools development, as well as hardware and software infrastructure for wearable computing solutions used in conjunction with VR and AR. Table 12 gives an overview about this subject, presenting eight papers published in the SVR events.

Table 12. Papers presenting technologies developed by the authors.

\begin{tabular}{|l|l|}
\hline \multicolumn{1}{|c|}{ Technology } & \multicolumn{1}{|c|}{ Year and page reference } \\
\hline Engine & $07 \mathrm{p} 51 ; 07 \mathrm{p} 92$ \\
\hline $\begin{array}{l}\text { Wearable } \\
\text { platform }\end{array}$ & $07 \mathrm{p} 77$ \\
\hline $\begin{array}{l}\text { Software } \\
\text { libraries }\end{array}$ & $04 \mathrm{p} 149 ; 04 \mathrm{p} 327 ;$ \\
$06 \mathrm{p} 171 ; 06 \mathrm{p} 245 ; 06 \mathrm{p} 373$
\end{tabular}




\section{Research Approaches Applied}

This section analyses the kinds of research approaches followed by the papers. With this analysis, we want to create a picture about the maturity of the research realized by our community in the areas comprised by SVR, similarly to what has been made by [5] and [6].

In order to scrutinize the research approaches, we based on a generally-accepted classification, described by Morrison and George [7]. According to these authors, research approaches include:

1. Formulative research;

2. Descriptive research;

3. Evaluative research;

4. Developmental research.

Formulative research represents original contributions to knowledge, by means of "the development and refinement of theories, models, or frameworks that govern research activities and support scientific progress through paradigm shifts" [7]. In other words, formulative papers are the so called "seminal" papers in some area. We could not identify any formulative paper among the papers analyzed in the present study.

Descriptive research describes theories or models to provide input for future research. Surveys are typical examples of descriptive papers. We could identify only four descriptive papers $(3.23 \%)$ in our analysis (see results in Table 13). Descriptive papers have relevant roles in important periodicals and are common in other scientific areas (e.g., comparison between different treatments for a disease, in medicine), but they do not have regular presence in Computer Science conferences. The small number of descriptive papers in SVR just reflects this trend in Computer Science. In our opinion, the exigency of an "original contribution" for a paper to be published in a conference intimidates the submission of good descriptive papers.

Evaluative research involves "methodologies that employ the scientific method, and usually consisting of theory or model generation or observation followed by hypothesis generation and testing" [7]. We identified thirteen evaluative papers in our analysis (10.48\%), which is still a small number, considering the importance of evaluative research. Again, this reflects an already indentified weakness of Computer Science in general [8], but that should be rectified for the maturity of the area as scientific research. It is important to clarify that we considered as evaluative papers only those whose main goal is to use the scientific method to study some hypothesis. We did not consider evaluative papers those that make tests to verify the performance or efficiency of a developed application or device. These papers are considered developmental papers, since their main goal is to present the developed application or device. 
Table 13. Papers classified according to their research approaches.

\begin{tabular}{|c|c|}
\hline $\begin{array}{l}\text { Research } \\
\text { approach }\end{array}$ & Year and page reference \\
\hline Formulative & (none) \\
\hline Descriptive & $\begin{array}{l}\text { 04p65; 04p207; } \\
\text { 06p183; 06p409 }\end{array}$ \\
\hline Evaluative & $\begin{array}{l}\text { 06p39; 06p77; 06p89; 06p135; 06p233; 06p323; 06p349; } \\
07 \text { p30; 07p143; 07p246; 07p263; } \\
\text { 08p196; 08p359 }\end{array}$ \\
\hline $\begin{array}{l}\text { Developmental } \\
\text { (generalizable) }\end{array}$ & 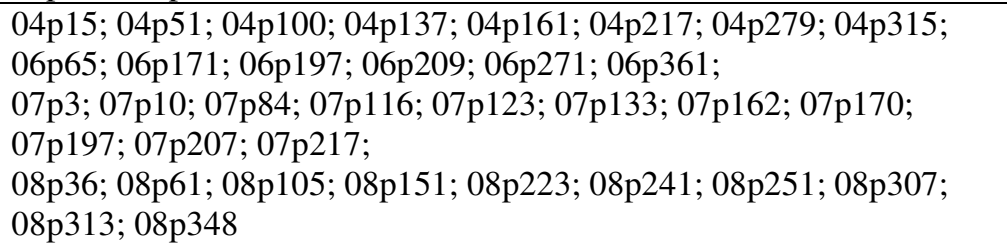 \\
\hline $\begin{array}{l}\text { Developmental } \\
\text { (specific) }\end{array}$ & 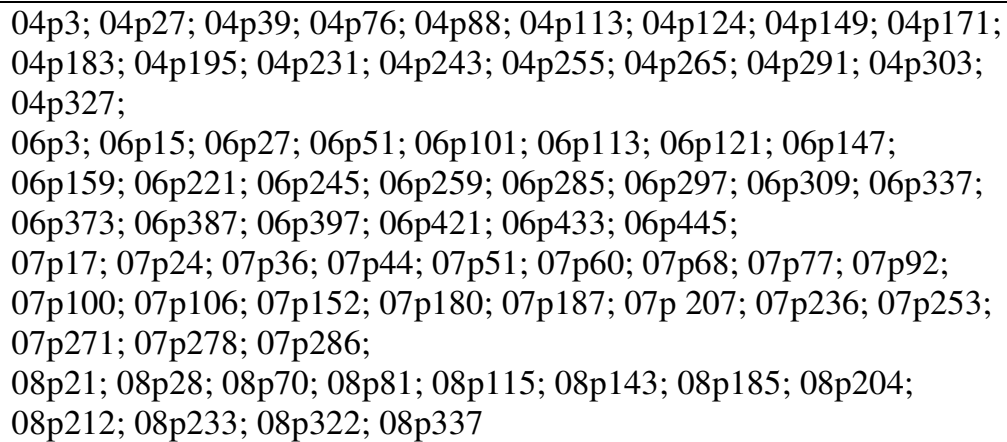 \\
\hline
\end{tabular}

Developmental papers represent the large majority of the analyzed papers $(86.29 \%)$, which is not a surprise, since SVR related areas are very technology-driven. In order to make a more detailed analysis, we decided to divide the developmental category into two subcategories: generalizable and specific. By generalizable developmental research we mean the development of methodologies or tools for the building of systems. In the fields covered by SVR, typical generalized developmental papers are those that present tools for the development of virtual environments or propose new simulation algorithms. By specific developmental research we mean the development of specific systems, such as an application in a specific area. Using this subdivision for developmental research, we identified thirty five $(28.23 \%)$ generalizable and seventy two $(58.06 \%)$ specific developmental papers.

The research approach analysis indicates the relative immaturity of research in SVR community, specially when compared to other Computer Science areas that have been increasing empirical research, such as Software Engineering [9] and CSCW [6]. Research in 
SVR community is much more directed to the development of specific applications. We can assume that, in part, this situation is caused by the fact that VR and related areas are younger than other areas in computing (the first conferences in VR date from the early 90's). Beyond, we cannot make a precise comparison between the SVR and the international VR communities, since it would be necessary a similar analysis of the papers presented in the relevant international conferences in VR. Therefore, we cannot conclude that this detected research immaturity is caused only by the freshness and high technological focus of the area.

\section{Final Considerations}

This paper analyzed all full papers accepted in SVR from 2004 to 2008 and classified them according to their language, international participation, main subject, major technologies used, and research approach.

Many SVR committees have been encouraging international participation and the publication of original and relevant papers. This initiative has lead to a number of Brazilian researchers writing their papers in English, hence giving an international visibility to recent VR and AR advances achieved in Brazil.

The publications present a standard pattern in terms of their main subjects. Some topics are more explored in one year than the others, but it is not possible to see any big shift in areas of research in the last four years.

Regarding our technologies analysis, it is important to state that most of technologies used by SVR community are open source and freely licensed. Further, they are objectoriented which facilitates program development. It is visible that many papers did not explicit which language is used, what consequently diminishes reproducibility. Furthermore, we conclude that SVR community went all the way to develop their own technologies to answer specific project requirements. So, this could be seen as an increased level of maturity.

Finally, regarding research approaches, since we deal with technology-driven areas, large majority of papers falls into developmental categories. However, the presented analysis indicates that our research community should pay more attention to evaluative and descriptive works.

\section{References}

[1] M. K. Zuffo, I. A. Souza, M. S. Pinho. Proceedings of the VII Symposium on Virtual and Augmented Reality. SBC, 2004. ISBN 978-85-7651-006-2.

[2] R. M. Costa, R. Tori, B. S. Meiguins. Proceedings of the VIII Symposium on Virtual and Augmented Reality. SBC, 2006. ISBN 978-85-7669-067-2.

[3] R. Tori, A. Raposo, J. C. Oliveira, A. Cardoso. Proceedings of the IX Symposium on Virtual and Augmented Reality. SBC, 2007. ISBN 978-85-7669-112-9. 
[4] A. Raposo, J. Kelner, L. S. Machado, R. Tori. Proceedings of the X Symposium on Virtual and Augmented Reality. SBC, 2008. ISBN 978-85-7669-167-9.

[5] R. L. Glass, V. Ramesh, I. Vessey. An Analysis of Research in Computing Disciplines. Communications of the ACM, 47(6): 89-94. 2004.

[6] J. Wainer, C. Barsottini. Empirical research in CSCW - a review of the ACM/CSCW conferences from 1998 to 2004. Journal of the Brazilian Computer Society, 13(3): 2736. September 2007.

[7] J. Morrison, J. F. George. Exploring the Software Engineering Component in MIS Research. Communications of the ACM, 38(7): 80-91. 1995.

[8] W. F. Tichy, P. Lukowicz, L. Prechelt, E. A. Heinz. Experimental evaluation in computer science: A quantitative study. Journal of Systems and Software, 28(1): 9-18. 1995.

[9] B. A. Kitchenham, S. L. Pfleeger et al. Preliminary guidelines for empirical research in software engineering. IEEE Transactions on Software Engineering, 28(8): 721-734. 2002. 